\title{
REDESAIN ALAT KERJA BERBASIS ANTROPOMETRI ORANG BALI DAN REMODELING SIKAP KERJA MENURUNKAN POSTURAL STRES PRAMUGRAHA HOTEL PURI SARON SEMINYAK-KUTA BALI
}

\author{
NK Dewi Irwanti \\ STIPAR Triatma Jaya Jl. Kubu Gunung, Dalung, Kuta - Bali, \\ Telp.(0361)412971/425761 \\ Email: nk_dewi_irwanti@yahoo.com
}

\begin{abstract}
Working with a trolley that is incompatible with anthropometry has risks in increasing postural stress, which manifests as fatigue and musculoskeletal complaints. This study aims to determine the room attendant fatigue and musculoskeletal complaints level when using a trolley; to find out the work posture score on activities using a trolley; to find out a trolley design which is compatible with Balinese anthropometry; to find out work posture score on the activity of using the trolley. This research was conducted experimentally using the same subject design (treatment by subject design). The number of samples was 14 employees. Two treatments were applied to the subjects, namely Period I or PI (the samples were working with the trolley) and Period II or PII (sample or room attendant Hotels working trolley according to Balinese anthropometry). Fatigue is measured using a questionnaire of 30 items of rating scale, musculoskeletal complaints using the Nordic body map. Measurement data were analyzed using descriptive and inferential analysis. Comparative analysis of the variables of fatigue, and muscle complaints using the Wilcoxon Test with a significance level of $5 \%(\alpha=0.05)$. The results showed that the mean fatigue and muscle complaints before and after work were significantly different where the value of $p<0.05$. Total RULA analysis score before treatment 6 , after treatment 3 . Work tool design is based on total ergonomic approach through TTG and SHIP approach.
\end{abstract}

Keywords: Trolley, Anthropometry, Postural Stress, RULA Analysis

\section{BAB 1. PENDAHULUAN}

\section{A. Latar Belakang}

Beberapa jenis pekerjaan mengharuskan pekerja untuk bekerja dengan postur kerja tidak alamiah sehingga berisiko meningkatkan postural stres yang manifestasinya berupa kelelahan dan keluhan otot skeletal. Salah satu peningkatan postural stres berasal dari aktivitas angkat angkut dan interaksi dengan alat bantu kerja berupa troli yang digunakan oleh pramugraha (housekeeper) hotel. Pada studi pendahuluan yang dilakukan dengan analisis metode RULA pada aktivitas angkat angkut menggunakan troli ini diperoleh skor 7 (tujuh) yang mengindikasikan bahwa pramugraha memiliki level risiko tinggi terhadap cidera otot dan perlu tindakan segera untuk

dilakukan perubahan (Susihono \& Irwanti, 2014).

Troli sampai saat ini menjadi alat bantu yang harus ada guna membantu penyelesaian aktivitas pramugraha di hotel. Troli difungsikan sebagai alat bantu untuk pengangkutan berbagai bahan seperti handuk, selimut maupun fasilitas isi ulang dan lainnya. Pemanfaatan troli yang tidak sesuai dengan kapasitas mengakibatkan pramugraha melakukan sikap kerja tidak alamiah (awkward posture). Liladrie (2010) menyebutkan $91 \%$ pramugraha mengalami keluhan otot skeletal saat bekerja yang disebabkan oleh postur kerja tidak alamiah. Sedangkan Grandjean (2007) menyatakan kelelahan dan keluhan otot disebabkan oleh 
Jurnal Manajemen Pelayanan Hotel Akademi Komunitas Manajemen Perhotelan Indonesia (Irwanti, halaman 106113) Vol 2, No 2 Edisi Juli-Desember 2018

postur kerja tidak alamiah diakibatkan oleh perancangan fasilitas yang kurang sesuai dengan antropometri sehingga akan mempengaruhi kinerja karyawan.

Troli yang digunakan di hotel umumnya merupakan produk import yang desainnya belum sesuai dengan antropometri pramugraha hotel di Bali. Sutajaya (2011) menyebutkan bahwa di dalam mendesain stasiun dan proses kerja, sampai saat ini belum mengacu kepada data antropometri pekerja yang ada di areal tempat mereka beraktivitas. Umumnya yang digunakan sebagai acuan adalah data sekunder yang ada pada literatur atau sumber bacaan yang relevan yang umumnya masih menggunakan ukuran orang barat. Sehingga dibutuhkan eksplorasi data dasar yang akan digunakan sebagai acuan di dalam membuat desain troli yang ergonomis bagi pramugraha hotel di Bali.

Desain troli harus memperhatikan
aspek karyawan untuk memberikan kemudahan dalam bekerja. Perbaikan melalui redesain alat dan remodeling sikap kerja dilakukan dengan pendekatan ergonomi yakni menggunakan data antropometri karyawan maupun pertimbangan lainnya seperti pendekatan konsep Teknologi Tepat Guna (TTG) (Manuaba, 2005a). Konsep TTG dalam desain troli akan dikaji secara sistemik, holistic, interdisipliner, dan partisipatori (SHIP) melalui tujuh kriteria, antara lain; a) teknis, troli didesain memperhatikan bahan baku yang digunakan dan ketepatan fungsinya agar mudah dalam perawatan dan penggantian material bahan bila terjadi kerusakan, b) ekonomis, artinya bahan yang digunakan lebih hemat, awet, tidak menimbulkan pemborosan, c) ergonomis, artinya bahwa desain mempertimbangkan kondisi kerja yang efektif, nyaman, aman, sehat, dan efisien (ENASE), dan memperhatikan dimensi antropometri karyawan, d) sosial budaya, artinya tidak menyimpang dari kebiasaan maupun nilai budaya setempat, desain memperhatikan heritage yang sudah menjadi warisan, e) hemat energi artinya tidak menambah beban karyawan dalam mengoperasikan dan tidak memerlukan tenaga maupun alat bantu lainnya untuk pengoperasian troli, f) ramah lingkungan artinya troli tidak memberikan efek buruk terhadap lingkungan seperti pemilihan cat pada handle, g) mengikuti trend atau sesuai dengan desain terkini sehingga memberikan efek nyaman dalam penggunaannya (Susihono \& Irwanti, 2014). Di samping itu melalui pendekatan SHIP akan terwujud desain stasiun dan proses kerja yang secara teknis sesuai dengan pekerjanya dan secara fisiologis tidak menimbulkan keluhan muskuloskeletal, tidak mengakibatkan beban kerja yang terlalu berat dan dapat memperlambat munculnya kelelahan (Manuaba, 2006 a; Azadeh, et al, 2007; Ercan, et al, 2006). Berdasarkan latar belakang masalah tersebut dapat dibuat rumusan masalah sebagai berikut; (1) Bagaimanakah menentukan kelelahan pramugraha pada saat beraktivitas menggunakan troli?, (2) Bagaimanakah menentukan keluhan muskuloskeletal pramugraha pada saat beraktivitas menggunakan troli?, (3) Bagaimanakah desain troli yang sesuai dengan antropometri orang Bali?, (4) Bagaimanakah skor postur kerja dan usulan remodeling sikap kerja pada metode RULA yang diperoleh pada aktivitas menggunakan troli?

\section{MATERI DAN METODE PENELITIAN}

Penelitian ini dilakukan secara eksperimental menggunakan rancangan sama subjek (treatment by subjek design). Jumlah sampel dihitung berdasarkan rumus Colton (1985) sehingga diperoleh jumlah sampel sebanyak 14 karyawan. Subjek mendapatkan dua perlakuan yaitu Periode I atau PI (sampel atau room attendant Hotel bekerja dengan trolley lama) dan Periode II atau PII (sampel atau room attendant Hotel bekerja 
dengan trolley sesuai antropometri orang Bali). Masing-masing perlakuan dilakukan selama 10 hari, washing out period selama 2 hari, dan adaptasi 2 hari.Kelelahan kerja diukur menggunakan kuesioner 30 item of rating scale, keluhan otot dengan menggunakan Nordic body map. Data hasil pengukuran dianalisis menggunakan analisis deskriptif dan inferensial. Analisis komparasi terhadap variabel kelelahan, dan keluhan otot menggunakan Wilcoxon Test dengan taraf signifikansi $5 \%(\alpha=0,05)$.

\section{HASIL DAN PEMBAHASAN \\ 1. Subjek Penelitian}

Karakteristik subjek penelitian yang meliputi variabel umur, berat badan, tinggi badan dan pengalaman kerja ditunjukkan seperti pada Tabel 1 berikut.

Tabel 1. Karakteristik Subjek Penelitian

\begin{tabular}{ccccc}
\hline Variabel & N & Range & Mean & SD \\
\hline Umur & 14 & 14,00 & 30,21 & 5,25 \\
Berat badan & 14 & 8,50 & 62,39 & 2,84 \\
Tinggi badan & 14 & 8,00 & 169,46 & 2,14 \\
IMT & 14 & 3,36 & 21,73 & 1,05 \\
Pengalaman kerja & 14 & 2,00 & 5,36 & 0,84 \\
\hline
\end{tabular}

Rerata umur subjek adalah 30,21 $\pm 5,25$ tahun, dengan rerata pengalaman kerja adalah 5,36 tahun. Hal ini menunjukkan subjek berada dalam usia produktif dan sudah berpengalaman bekerja dibidangnya. Indeks massa tubuh berada pada rentang 3,36 - 1,05 dengan rerata 21,73. Indeks masa tubuh ini berada pada pada kondisi normal. Kondisi subjek ini masih berada dalam keadaan fisik yang optimal untuk melakukan pekerjaan karena dalam usia produktif dan kondisi fisik yang baik. Kondisi umur berpengaruh terhadap kemampuan kerja fisik atau kekuatan otot seseorang. Kemampuan fisik maksimal seseorang dicapai pada umur antara 25 -35 tahun dan akan terus menurun seiring dengan bertambahnya umur (Kroemer and Grandjean, 2000).

\section{Data Antropometri Subjek}

Untuk mengetahui kesesuaian antara trolley yang digunakan dengan ukuran tubuh subjek dilakukan pengukuran antropometri dengan menggunakan persentil 5, 50, dan 95, disajikan pada Tabel.2.

Tabel.2

Data Antropometri pada Persentil 5, 50, dan 95

\begin{tabular}{lccc}
\hline & Persentil & & \\
Antropometri & 5 & Persentil 50 & Persentil 95 \\
\hline Tinggi badan $(\mathrm{cm})$ & 165,94 & 169,46 & 172,21 \\
Tinggi siku berdiri $(\mathrm{cm})$ & 103,69 & 107,60 & 110,64 \\
Panjang jangkauan $(\mathrm{cm})$ & 61,91 & 65,63 & 68,52 \\
Lebar telapak tangan & & & \\
$(\mathrm{cm})$ & 9,53 & 10,50 & 11,26 \\
\hline
\end{tabular}


Panjang telapak tangan (cm)

18,96

19,44

Redesan troli mengacu pada beberapa dimensi tubuh yang harus diperhitungkan agar selanjutnya alat yang dibuat mampu memberikan kenyamanan saat digunakan oleh pemakai. Troli yang
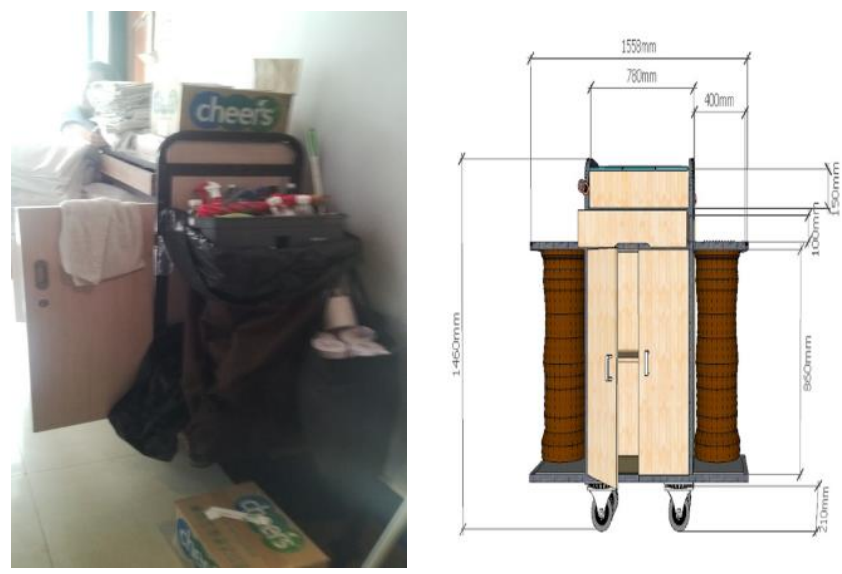

\section{Lingkungan Kerja}

Lingkungan kerja tempat subjek penelitian bekerja meliputi kondisi suhu, kelembaban relatif, kecepatan angin, dan intensitas suara. Data kondisi lingkungan ini diuji normalitasnya dengan menggunakan uji Shapiro-Wilk dan diperoleh hasil data lingkungan belum dimodifikasi dan yang telah disesuaikan dengan antropometri mahasiswa serta disesuaikan dengan fungsinya tampak pada gambar berikut.

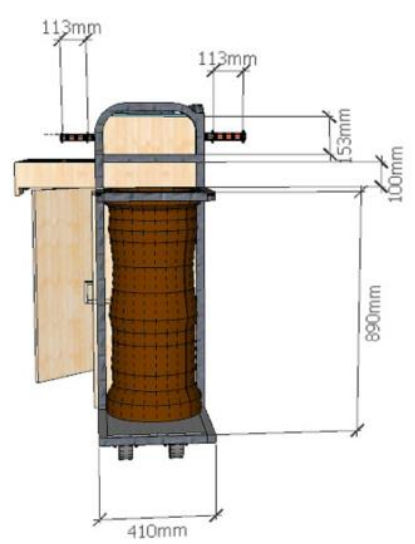

kerja tersebut pada kelompok Perlakuan I maupun perlakuan II terdistribusi secara normal $(p>0,05)$. Hasil analisis pengukuran kondisi lingkungan kerja pada kelompok perlakuan I dan perlakuan II seperti pada Tabel 3 berikut.

Tabel 3. Kondisi lingkungan tempat penelitian

\begin{tabular}{|c|c|c|c|c|c|c|c|c|}
\hline \multirow[t]{2}{*}{ No } & \multirow{2}{*}{\multicolumn{2}{|c|}{ Parameter }} & \multicolumn{2}{|c|}{ Periode I } & \multicolumn{2}{|c|}{ Periode II } & \multirow{2}{*}{$\begin{array}{l}\text { Nilai } \\
\mathrm{p}\end{array}$} & \\
\hline & & & Rerata & SB & Rerata & SB & & \\
\hline 1. & Suhu keri & & 28,62 & 0,64 & 28,44 & 0,63 & 0,41 & \\
\hline 2. & Suhu bas & & 21,37 & 0,81 & 21,19 & 0,91 & 0,45 & \\
\hline 3. & Kelembab & & 76,48 & 1,70 & 76,62 & 1,70 & 0,76 & \\
\hline 4. & $\begin{array}{l}\text { Intensitas } \\
(\mathrm{dbC})\end{array}$ & suara & 56,53 & 1,50 & 56,48 & 1,59 & 0,88 & \\
\hline 5. & $\begin{array}{l}\text { Intensitas } \\
\text { (luks) }\end{array}$ & cahaya & 247,23 & 1,04 & 246,97 & 1,60 & 0,47 & \\
\hline & & & & & $\begin{array}{l}\text { Semu } \\
\text { seper }\end{array}$ & $\begin{array}{l}\text { kom } \\
\text { terter }\end{array}$ & $\begin{array}{l}\text { nen } \\
\text { pada }\end{array}$ & $\begin{array}{c}\text { lingkungan } \\
\text { Tabel } 2\end{array}$ \\
\hline
\end{tabular}


menunjukkan bahwa pada kelompok perlakuan I maupun kelompok perlakuan II masih dalam batas-batas adaptasi untuk melakukan suatu aktivitas kerja. Variabel suhu kering, suhu basah, kelembaban, kecepatan angin, dan intensitas suara tidak mempunyai perbedaan yang nyata antara masing-masing kelompok perlakuan $(p>0,05)$, sehingga dapat dinyatakan bahwa kondisi lingkungan antara kelompok perlakuan I dan perlakuan II adalah sama. Nilai ambang batas dari suhu udara untuk pekerja adalah $33 \square \mathrm{C}$ dan kelembaban relatif pekerja orang Indonesia yang masih tergolong nyaman adalah antara $70 \%$ $80 \%$ (Manuaba, 1998). Nilai ambang batas intensitas suara tertinggi yang masih dapat diterima tenaga kerja tanpa mengakibatkan gangguan daya dengar yang tetap untuk waktu kerja tidak lebih dari 8 jam sehari adalah 85 dBA (BSN, 2004).

\section{Analisis Kelelahan}

Hasil analisis analisis kelelahanan dapat dilihat pada Tabel 4.

Tabel 4

Hasil Analisis Kelelahan Pramugraha Hotel Puri Saron

\begin{tabular}{llcccccc}
\hline $\mathrm{N}$ & \multirow{2}{*}{ Variabel } & $\mathrm{n}$ & \multicolumn{2}{c}{ Periode I } & \multicolumn{2}{c}{ Periode II } & $\mathrm{p}$ \\
\cline { 4 - 7 } $\mathrm{O}$ & & & Rerata & $\mathrm{SB}$ & Rerata & $\mathrm{SB}$ & \\
\hline 1. & Kelelahan pre & 14 & 42,18 & 3,48 & 41,79 & 3,54 & 0,461 \\
2. & Kelelahan post & 14 & 82,29 & 6,54 & 54,71 & 2,20 & 0,000 \\
& & & & & & 1 \\
3. & $\begin{array}{l}\text { Beda } \\
\text { kelelahan pre- } \\
\text { post }\end{array}$ & 14 & 0,54 & 1,54 & 12,93 & 3,80 & 0,000 \\
\hline
\end{tabular}

Tabel 5.6 menunjukkan bahwa rerata kelelahan sebelum bekerja pada Periode I adalah 42,18 $\pm 3,48$ dan pada Periode II adalah 41,79 $\pm 3,54$ dengan nilai $p=0,4610$. Hal ini berarti bahwa kelelahan sebelum bekerja pada kedua periode tidak berbeda bermakna $(p>0,05)$. Artinya bahwa kelelahan sebelum bekerja adalah komparabel.

Karena rerata skor kelelahan sebelum bekerja komparabel maka analisis efek perlakuan terhadap kelelahan diuji berdasarkan rerata skor kelelahan setelah bekerja pada Periode

I dan Periode II. Rerata skor kelelahan pada periode I adalah 82,29 $\pm 6,54$ dan pada Periode II $54,71 \pm 2,20$. Analisis kemaknaan dengan uji $t$-paired menunjukkan bahwa nilai $p=0,0001$. Ini berarti bahwa rerata kelelahan kerja pada kedua periode setelah bekerja adalah berbeda bermakna $(p<0,05)$.

5. Analisis

\section{Muskuloskeletal}

Hasil analisis keluhan

muskuloskeletal dapat dilihat pada Tabel 5.

Tabel 5 
Hasil Analisis Keluhan Muskuloskeletal Pramugraha Hotel Puri Saron

No

$\mathrm{n} \frac{\text { Periode I }}{\text { Periode II }}$ Nilai

Variabel

a

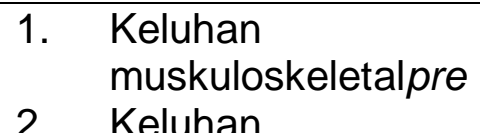

2. Keluhan

muskuloskeletalpost

$\begin{array}{llllll}14 & 36,25 & 2,9 & 36,32 & 2,63 & 0,672 \\ & & 7 & & & 0 \\ 14 & 66,64 & 5,4 & 47,39 & 4,74 & 0,000 \\ & & 8 & & & 1 \\ 14 & 0,07 & \begin{array}{l}0,5 \\ 9\end{array} & 19,25 & 3,99 & 0,000 \\ & & 9 & & & 1\end{array}$

3. Beda keluhan muskuloskeletal pre-post

Tabel 5.7 menunjukkan bahwa rerata keluhan muskuloskeletal sebelum bekerja pada Periode I adalah 36,25 \pm 2,97 dan pada Periode II adalah 36,32 \pm 2,63 dengan nilai $p=0,6720$. Hal ini berarti bahwa keluhan muskuloskeletal sebelum bekerja pada kedua periode tidak berbeda bermakna $(p>0,05)$. Artinya bahwa keluhan muskuloskeletal kedua periode adalah sama atau komparabel.

Karena rerata skor keluhan muskuloskeletal sebelum bekerja komparabel maka analisis efek perlakuan terhadap keluhan muskuloskeletal diuji berdasarkan rerata skor keluhan musculoskeletal setelah bekerja pada Periode I dengan Periode
II setelah bekerja. Rerata skor keluhan muskuloskeletal pada Periode I adalah $66,64 \pm 5,48$ dan pada Periode II adalah $47,39 \pm 4,74$. Analisis kemaknaan dengan uji $t$-paired menunjukkan bahwa nilai $p=0,0001$. Hal ini berarti bahwa rerata keluhan muskuloskeletal setelah bekerja pada kedua periode adalah berbeda bermakna $(p<0,05)$.

\section{Hasil Analisis RULA}

Analisis RULA dilakukan berdasarkan postur kerja saat mendorong troli perlengkapan. Berdasarkan analisis RULA diperoleh skor seperti Tabel 6 berikut.

Tabel 6 Total Skor Analisis RULA

\begin{tabular}{|c|c|c|}
\hline $\mathrm{N}$ Aktivitas & Total Skor Periode I & Total Skor Periode II \\
\hline 0 & Bagian kanan $\quad$ Bagian kiri & $\begin{array}{ll}\text { Bagian } & \text { Bagian kiri } \\
\text { kanan } & \end{array}$ \\
\hline
\end{tabular}

1 Mendorong troli $\quad 6 \quad 6 \quad 6 \quad 3$




\section{Gambar 12.1 Sikap Kerja Membungkuk (PI) \\ Gambar 12.2 \\ Hasil Analisis Rula \\ Dari Sisi Kanan (PI) \\ Gambar 12.3 \\ Hasil Analisis Rula \\ Dari Sisi Kiri (PI)}

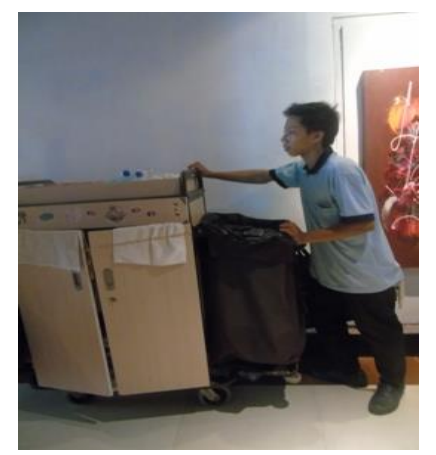

Gambar 12.4

Sikap Kerja

Mendorong troli (PII)

\section{SIMPULAN}

Dari hasil analisis dan pembahasan, dapat disimpulkan hal berikut.

a. Redesain alat kerja berbasis antropometri orang Bali dan remodeling sikap kerja menurunkan kelelahan pramugraha hotel PS

b. Redesain alat kerja berbasis antropometri orang Bali dan remodeling sikap kerja menurunkan keluhan otot pramugraha hotel PS

c. Redesain alat kerja berbasis antropometri orang Bali dan remodeling sikap kerja dengan analisis RULA menjadikan penurunan pada level resiko kerja.

\section{DAFTAR PUSTAKA}

Azadeh, A., Fam, M., Garakani, M.M. 2007. A Total Ergonomis Design Approach to Enhance the Productivity in A Complicated Control System. Journal of Information Technology. 6 (7): $1036-1042$.

Colton, T. 1985. Statistika Kedokteran. (Terjemahan R. Sanusi). Yogyakarta: Gadjah Mada University Press.

Ercan, S., \& Erdinc, O. 2006. Challenges of Leardership in Industrial Ergonomis Projects. Journal Istanbul Ticaret Universitesi Fen Bilimleri Dergisi. Vol.5 (9): 119 127.

Grandjean, E. 2007. Fitting the task to the Man. A TeAbianbiu Residencetbook of Occupational Ergonomis. 4th Edition. London: Taylor \& Francis.

Liladrie, S. 2010. Do not disturb, please clean room': Hotel housekeepers in greater Toronto. Race \& Class, 52(1), 57-69. Available from http://ezproxy.library,unlv.edu/logi n?url=http://search.ebschohost.c 
om/login.aspx?direct=true\&db=ap h\&AN=52286417\&site $=$ ehost -

live. Acessed on July 20nd. 2015

Manuaba, A. 2005c. Pendekatan Total

Ergonomi Perlu Untuk Adanya

Proses Produksi dan Produk yang Manusiawi, Kompetitif, dan Lestari. Makalah dipresentasikan pada Seminar Nasional Ergonomi "Aplikasi Ergonomi Dalam Industri", Forum Komunikasi Teknik Industri Yogyakarta dan Perhimpunan Ergonomi Indonesia (PEI). Yogyakarta, 27 Maret.

Susihono \& Irwanti, 2014. Desain Troli Tidak Ergonomis Meningkatkan Postural Stres Pekerja Pramugraha di Hotel PS Bali. Prosiding Seminar Nasional Kepariwisataan dan Diseminasi Hasil Penelitian 2914. ISBN: 978602-71208-0-8

Sutajaya, IM \& Ristiati, NP. 2011. Perbaikan Kondisi Kerja Berbasis Kearifan Lokal Yang Relevan Dengan Konsep Ergonomi Untuk Meningkatkan Kualitas Kesehatan Dan Produktivitas Pematung Di Desa Peliatan Ubud Gianyar. Jurnal Penelitian dan Pengembangan Sains \& Humaniora, 5(3), 259-270. 